University of Wollongong

Research Online

Faculty of Business - Papers (Archive)

Faculty of Business and Law

$1-1-2017$

A simple endogenous growth model with endogenous fertility and environmental concern

Simone Marsiglio

University of Wollongong, simonem@uow.edu.au

Follow this and additional works at: https://ro.uow.edu.au/buspapers

Part of the Business Commons

Research Online is the open access institutional repository for the University of Wollongong. For further information contact the UOW Library: research-pubs@uow.edu.au 


\title{
A simple endogenous growth model with endogenous fertility and environmental concern
}

\author{
Abstract \\ We analyze the implications of endogenous fertility choices on both economic and environmental \\ performances in a stylized AK-type growth model. Differently from what traditionally assumed in the \\ growth and environment literature, we allow pollution to be not only a by-product of productive activities \\ by firms but also a result of households' behavior, as suggested by the celebrated IPAT equation. We \\ show that along the balanced growth path equilibrium, economic growth may be non-monotonically \\ related to the population growth rate as agents care for the environment; moreover, demographic policies \\ can be used both to achieve win-win outcomes (simultaneously fostering economic growth and \\ improving environmental quality) and to stabilize the otherwise non-monotonic economic and population \\ growth relationship.

\section{Disciplines \\ Business}

\section{Publication Details} \\ Marsiglio, S. (2017). A simple endogenous growth model with endogenous fertility and environmental \\ concern. Scottish Journal of Political Economy, 64 (3), 263-282.
}




\title{
A Simple Endogenous Growth Model with Endogenous Fertility and Environmental Concern
}

\author{
Simone Marsiglio* \\ Forthcoming in Scottish Journal of Political Economy
}

\begin{abstract}
We analyze the implications of endogenous fertility choices on both economic and environmental performances in a stylized AK-type growth model. Differently from what traditionally assumed in the growth and environment literature, we allow pollution to be not only a by-product of productive activities by firms but also a result of households' behavior, as suggested by the celebrated IPAT equation. We show that along the balanced growth path equilibrium, economic growth may be non-monotonically related to the population growth rate since agents care for the environment; moreover, demographic policies can be used both to achieve win-win outcomes (simultaneously fostering economic growth and improving environmental quality) and to stabilize the otherwise non-monotonic economic and population growth relationship.
\end{abstract}

Keywords: Economic Growth, Endogenous Fertility, Environmental Quality

JEL Classification: J10, J11, O40, O41, Q50, Q56

\section{Introduction}

In the last decades a growing share of the economic literature has tried to analyze, on the one hand, the mutual implications between economic growth and environmental degradation (see Xepapadeas, 2005, for a survey) and, on the other hand, those between economic performance and demographic growth (see Bloom et al., 2003). Even among policymakers it has recently emerged a wide consensus on the fact that population, economy and environment are deeply interrelated, thus the problem of sustainable development cannot be dealt with without a clear understanding of their joint implications (UNEP, 2012). The nature and intensity of such interrelations have been extensively studied from an empirical point of view since the first introduction of the IPAT equation (Ehrlich and Holdren, 1971), stating that environmental impacts depend on population, affluence (consumption or production), and technology. Several modifications of the IPAT equation have been advanced over time (see, among others, the Kaya identity and the STIRPAT equation proposed by Kaya, 1990, and Rosa and Dietz, 1998, respectively), and it seems now clear that each of these three factors has a concrete and different impact on the environment (for a recent survey, see Rosa and Dietz, 2012). Despite such a large body of empirical works, very few are the theoretical studies aimed at addressing this issue. Indeed, only recently theoretical works have started to analyze the joint interactions among population, economic growth and environment. However, for tractability purposes this has been done by assuming that either demographic change is exogenous (Boucekkine et al., 2014; Azomahou et al., 2015), or economic growth is exogenous by abstracting from capital accumulation (Bosi and Desmarchelier, 2013),

\footnotetext{
${ }^{*}$ University of Wollongong, School of Accounting, Economics and Finance, Northfields Avenue, Wollongong 2522 NSW, Australia. Contact: simonem@uow.edu.au. I am indebted to two anonymous referees for their constructive comments on an earlier draft of the paper, helping me to substantially clarify and improve the paper. All remaining errors and omissions are my own sole responsibility.
} 
or environmental dynamics is independent of the emissions generated by productive activities (Marsiglio, 2011; Constant et al., 2014), which are all clear oversimplifications of reality.

Our paper tries to extend this literature by simultaneously analyzing the mutual interplays between population growth, economic growth and the environment. It thus relates to two different branches of the literature, both finding their origin in the seminal work by Malthus (1798) and aiming at understanding the nature of the relation between demographic changes and economic and environmental performance, respectively. The potential implications of population growth for economic performance are well known and several authors have discussed the channels through which demography interacts with economic growth (see among others, Barro and Becker, 1989; Boserup, 1986; Kelley, 1988, Simon, 1981). Despite the huge body of works, a shared view on the issue has not arisen yet, and alternative (pessimistic, optimistic and neutral) views point out that population growth may be either beneficial or detrimental or uninfluential at all for economic activities according to a wide range of circumstances (see Bloom et al., 2003, for a survey of such alternative views, both from theoretical and empirical points of view). Indeed, empirical evidence suggests that there might exist a non-monotonic relationship between population and economic growth (Kelley and Smith, 1995; Boikos et al., 2013), and thus understanding a priori the sign of such a relation is not possible. Only few works have been able to explain from a theoretical standpoint what might cause such an eventual non-monotonicity (Yip and Zhang, 1997; Boucekkine and Fabbri, 2013; Prettner, 2014), and our work contributes to this limited literature stream by proposing an alternative channel related to environmental concern. Also the relation between demography and the environment has been extensively studied (see Panayotou, 2000, for a survey), and the environment has been interpreted in terms of either natural resources or environmental quality. While the former concept has been the focus of theoretical works, empirical studies have mainly focused on the latter. Indeed, the main emphasis in theoretical works has traditionally been placed on the extra stress generated by population growth on the limited availability of land and natural resources (see, among others, Solow, 1974; Cigno, 1981; Dasgupta, 1995; Nerlove, 1991; Peretto and Valente, 2015), while most of the empirical works have focused on the impacts of population changes on environmental quality or pollution (Kaya, 1990; Rosa and Dietz, 1998). An important conclusion of such an empirical literature is related to the fact that environmental deterioration depends not only on economic activities (eventually net of green technological progress) but also on human population; however, among the few theoretical works that relate population growth to environmental quality (Harford, 1997, 1998; Schou, 2002; Jöst and Quaas, 2010) none addresses the specific role of population as a separate (from economic activities) driver of pollutant emissions, as suggested by the empirical evidence on the IPAT equation (Rosa and Dietz, 2012). We thus contribute also to this limited branch of the literature by developing a more comprehensive approach to the role of population growth as a source of environmental degradation per se.

The papers most closely related to ours are Schou (2002) and Jöst and Quaas (2010) which both analyze an economic growth model with endogenous fertility choices and environmental quality. However, our goals are substantially different from theirs which mainly focus on how to restore the social optimum in a decentralized economy. Indeed, our main interest is understanding what population growth may imply for economic and environmental performance and how population policy can be used to affect both economic and environmental outcomes 1 . More specifically, our paper analyzes the mutual relationships among population, economy and environment by simultaneously considering endogenous fertility choices and the polluting effect associated with both population and economic dynamics. In order to analyze the nature of

\footnotetext{
${ }^{1}$ Our model's formulation, since assuming that environmental quality is a stock variable and abstracting from environmental policy, does not allow to discuss issues related to the inefficiency generated by the environmental externality and the eventual implementation of the first best. Extending the analysis along this direction would result in some additional complications precluding us to analyze in a neat and intuitive way the role of demographic policy, which is our main focus. We thus postpone this type of analysis for future research and we focus on a decentralized economy in which population policy can be used to improve environmental outcomes. This allows us to better understand the extent to which in a real world situation demographic policy might represent an effective tool at policymakers' disposal.
} 
such interplays in the simplest possible framework, we focus on an AK-type model of endogenous growth with endogenous demographic change and environmental interaction, abstracting completely from abatement activities. Within such a stylized context, we can stress the impact of demographic change on both economic and environmental performances. Apart from the environmental extension, our model closely resembles Razin and Yuen's (1995) specification of human capital accumulation and population growth which allows to stress the quantity-quality trade-off of children, that is higher population growth tends to lower economic performance through the (human) capital accumulation channel (Becker and Lewis, 1973). Once the environment is introduced in the analysis, the growth and demography relationship is no longer so trivial since population growth affects economic performance through an additional channel due to a certain degree of environmental concern. For any strictly positive value of the green preference parameter, the relationship between demographic and economic growth turns out to be non-monotonic as suggested by empirical evidence (Kelley and Smith, 1995; Boikos et al., 2013). Specifically, for small values of the fertility rate population growth is beneficial for economic performance, while for large values it is detrimental for growth. Moreover, demographic policy, through its ability to simultaneously affect both capital accumulation and environmental quality, turns out to be an effective tool in order to achieve win-win outcomes (Porter and van der Linde, 1995; Ansuategi and Marsiglio, 2016), promoting simultaneously both economic growth and environmental improvements. Thus, even in absence of specific environmental policy, demographic policy can be used not only to affect effect economic growth but also to affect environmental performance. In its simplicity the model is striking allowing to reconcile theory with empirics (on the growth-demography nexus) and presenting interesting policy implications (on eventual win-win outcomes).

This paper proceeds as follows. Section 2 introduces our stylized model, combining the traditional endogenous fertility and economic growth theory with the growth and environment theory. Differently from what traditionally assumed in the growth and environment literature, we allow pollution to be not only a by-product of productive activities by firms but also a result of households' behavior. In this framework, as suggested by the IPAT equation (Ehrlich and Holdren, 1971), since both the economic output and the population size are potential and independent sources of environmental quality deterioration, we can further stress the critical role played by demographic change in the process of sustainable development. Section 3 discusses the steady state outcome which is characterized by a balanced growth path (BGP) equilibrium along which the fertility rate is constant and economic and environmental variables grow at a strictly positive rate. It also derives our main results related to the non-monotonicity of the growth and population nexus, and the possibility to rely on demographic policy in order to achieve win-win outcomes. While the results are straightforward whenever exogenous factors are controlled for, when they are allowed to vary the picture is a bit more complicated; however, also in this framework, we can conclude that our results, supported also by a numerical exercise, still hold true. Section 4 focuses more specifically on the role of demographic policy and how it can effectively be used in order to stabilize the otherwise non-monotonic relationship between economic (or also environmental) performance and population growth. Indeed, specific policies aiming to maximize economic performance may bring the two forces affecting the nature of such a relationship (i.e., the environment and output effect) to perfectly cancel out. As usual section 5 presents concluding remarks and points out directions for future research.

\section{The Model}

The model is a Ramsey (1928) model of economic growth with endogenous fertility and environmental interactions. Households receive wages, purchase a consumption good, choose how much to save and how much of their time to allocate to child rearing rather than productive activities; their lifestyle and daily life activities produce waste and thus contribute to overall pollution ${ }^{2}$. Firms produce the consumption good

\footnotetext{
${ }^{2}$ As emphasized by the US National Academy of Sciences: "The more people there are in the world, the greater is the demand put on resources to provide food, energy, clothing and shelter for them. All these activities necessarily involve emissions of
} 
emitting some pollutant. Pollution, generated by both firms and households, deteriorates the environment. In the following, lowercase and uppercase letters indicate per capita and aggregate variables, respectively. As a matter of expositional simplicity, we will use the terms nurturing and child rearing time, fertility rate and population growth rate interchangeably.

The household's problem consists of maximizing its welfare given the law of motion of (human) capital, $H_{t}$, and the evolution of the household dynasty, $N_{t}$, by choosing how much each member should consume, $c_{t}$, and how much time should dedicate to raise children, $n_{t}$. Welfare is defined according to the Benthamite criterion, thus it is the infinite discounted sum ( $\rho$ is the pure rate of time preference) of the product between instantaneous utilities, which depend both on consumption and environmental quality, $E_{t}$, and the household size (as traditionally assumed in growth theory, fertility is not an argument of the utility function 3 , Boucekkine and Fabbri, 2013). The instantaneous utility function is assumed to take the following isoelastic form: $u\left(c_{t}, E_{t}\right)=\frac{\left(c_{t} E_{t}^{\beta}\right)^{1-\sigma}}{1-\sigma}$, where $\sigma>0$ is the inverse of the intertemporal elasticity of substitution and $\beta \geq 0$ represents the green preferences parameter (Smulders and Gradus, 1996). The birth rate, $b_{t}$ (we abstract from mortality for the sake of simplicity), determines the evolution of the dynastic household: $\dot{N}_{t}=b_{t} N_{t}$; as in Razin and Yuen (1995) and Tournemaine and Luangaram (2012) children are created according to the following production function $b_{t}=b n_{t}^{\theta}$ where $n_{t} \in[0,1]$ represents the time allocated to child rearing (nurturing) activity while $b>0$ and $\theta \in(0,1)$ are efficiency parameters. (Human) Capital accumulates according to the difference between (labor) income and consumption $4 \dot{H}_{t}=\left(1-n_{t}\right) w_{t} H_{t}-c_{t}$, where $1-n_{t}$ represents the time devoted to productive (labor) activities while $w_{t}$ is the remuneration (wage) rate5. Given the initial capital and household's size conditions, $H_{0}$ and $N_{0}$ respectively, the household's problem reads as:

$$
\begin{array}{rlrl}
\max _{c_{t}, n_{t}} & W=\int_{0}^{\infty} \frac{c_{t}^{1-\sigma} E_{t}^{\beta(1-\sigma)}}{1-\sigma} N_{t} e^{-\rho t} d t \\
\text { s.t. } & \dot{H}_{t}=\left(1-n_{t}\right) w_{t} H_{t}-N_{t} c_{t} \\
& \dot{N}_{t}=b n_{t}^{\theta} N_{t} .
\end{array}
$$

Final output is produced competitively according to a linear technology employing only capital:

$$
Y_{t}=A H_{t}
$$

where $A>0$ is a technological parameter. Maximization of instantaneous profits implies a constant remuneration rate: $w_{t}=A$.

The evolution of environmental quality depends on the difference between its pollution absorption capacity and generated pollution, $P_{t}$. The pollution absorption capacity is assumed to be linear in environmental quality with $\xi>0$ measuring the natural rate of absorption; this implies that environmental quality is

greenhouse gases" (NAS 1992). Recent studies show that population does not represent only a scale factor in transforming per capita emissions in total emissions, but pollution and population are nonlinearly related and the intensity of the relation varies substantially with the population size (Cole and Neumayer, 2004).

${ }^{3}$ Note that assuming that fertility is not an argument of the utility function does not mean that households do not have any incentive to have children. Indeed, in our Benthamite specification of welfare, the growth rate of the household's size (i.e., the fertility rate) enters the welfare function through the household size channel. See Boucekkine and Fabbri (2013) and Marsiglio (2014) for a recent discussions of the implications for economic and demographic growth of adopting the Benthamite rather than the Millian principle as a welfare criterion.

${ }^{4}$ Note that the even interpreting capital simply as human capital would not compromise the model's interpretation. Indeed, the human capital accumulation equation is consistent with a one-sector production technology (Barro and Sala-i-Martin, 2004) in which output is either consumed or invested. If consumption is larger than output then investment will be negative and as a result there will be human capital decumulation; this however does not mean that human capital will be consumed.

${ }^{5}$ This framework can thus be interpreted as a model with leisure, where the endogenously determined leisure time $\left(n_{t}\right)$ is completely devoted to raise children. Even if with a different goal and approach, see Galindev (2011) who analyzes an unified growth model in which partly leisure activities depend on the rate of fertility. 
unbounded, meaning that we are focusing on ecological processes taking the form of renewable resources (Smulders, 1999). Pollution is assumed to be partly a side product of output produced by firms and partly a side product of the waste produced by households: $P_{t}=\mu Y_{t}^{\phi} N_{t}^{\omega}$, where $\mu, \phi, \omega \geq 0$ are measures of environmental efficiency. This means that, in line with the IPAT equation (Ehrlich and Holdren, 1971), production activities are not the only source of pollution and, as conjectured by the STIRPAT equation (Rose and Dietz, 1998), production and population do not necessarily need to have the same impact on the environment ${ }^{6}$. Thus, given its initial condition, $E_{0}$, the dynamics of environmental quality is given by the following differential equation:

$$
\dot{E}_{t}=\xi E_{t}-\nu H_{t}^{\phi} N_{t}^{\omega}
$$

where $\nu=\mu A^{\phi}$. This specification of pollution 7 allows to stress that the behavior of both firms and households is crucial in determining the overall amount of pollution produced. Indeed, two similar countries (same $\nu, \phi$ and $\omega$ ) might generate different levels of pollution because of a difference in either their productive capacity or in their population size. In the former case the driver of eventual differences in environmental outcomes is represented by the environmental efficiency of firms, while in the latter by the environmental attitude of households. Note that if $\omega=\phi$ production and population have exactly the same impact on the environment (as stated by the IPAT equation), while if $\omega=0$ pollution depends only on productive activities by firms and not also on household's activities (as traditionally assumed in the growth and environment literature). Even if evidence is mixed, $\omega>0$ seems to be the most interesting case from an empirical point of view, since several studies (Cole and Neumayer, 2004; Galeotti et al., 2011) show that the population size and/or related variables (as population density) are an important determinant of polluting emissions, independent and clearly different from affluence-related factors $8^{8}$ (i.e., consumption and production).

\section{BGP Analysis}

In general equilibrium, markets clear and agents maximize their objective function. The closed-economy resource constraint implies that output is allocated between consumption and investments in capital accumulation: $Y_{t}=N_{t} c_{t}+\dot{H}_{t}$. We focus on the BGP equilibrium, namely an outcome in which variables grow at constant rates. It is possible to show that per capita variables grow at the same constant rate and the following result holds.

Proposition 1. Assume that $\left.(1+\beta \phi)(1-\sigma)(1-\bar{n}) A+[\sigma+\beta \omega(1-\sigma)] b \bar{n}^{\theta}<\rho<(1-\bar{n}) A+\beta(\phi+\omega)(1-\sigma)\right] b \bar{n}^{\theta}$

\footnotetext{
${ }^{6}$ Indeed, our specification of pollution is consistent with the STIRPAT equation advanced by Rose and Dietz (1998). Differently from the IPAT equation, the STIRPAT does not restrict the analysis to the case in which the different factors have the same impact on the environment (i.e., the elasticities of the three forces, population, affluence and technology, do not necessarily need to coincide).

${ }^{7}$ Note that our specification of the production function and emissions is consistent with the material balance requirements, since the only production factor (i.e., capital) is a nonmaterial input (Ebert and Welsch, 2007).

${ }^{8}$ Several works have recently tried to analyze the impact of population on the environment (Lutz et al., 2002), and a growing consensus seem to emerge on the fact that the population size and its growth rate play a crucial role in the rise in emissions that we have witnessed over the last century. Despite the effects of technological progress that partially offset emissions, Harrison (1994) finds that population growth is responsible of about $36 \%$ of emission growth in the 1965-1989 period, while the remaining $64 \%$ is attributable to per capita consumption. Cole and Neumayer (2004), by distinguishing the effects of population on $\mathrm{CO}_{2}$ and $\mathrm{SO}_{2}$, show that some substantial differences exist according to the type of pollutant considered. Indeed, while in the $\mathrm{CO}_{2}$ case pollution rises proportionally with population and other demographic factors (urbanization rate and household size) are relevant in explaining the pollution trend, in the case of $\mathrm{SO}_{2}$ the relation between population and pollution is U-shaped and other demographic factors are not that important. More recently, Galeotti et al. (2011) analyzing a long time series for 17 OECD countries show that the population is a significant independent explanatory variable of $\mathrm{CO}_{2}$ emissions both when its effects on income are and are not accounted for.
} 
and $\phi<\sigma<\frac{A}{A+\theta b}$; then along the BGP the time allocated to child rearing activity is constant and equal to:

$$
\bar{n}=\left[\frac{\sigma \theta b}{(1-\sigma) A}\right]^{\frac{1}{1-\theta}} \in(0,1),
$$

while the economic and environmental growth rates are strictly positive and respectively given by:

$$
\begin{aligned}
\gamma & =\gamma_{c}=\gamma_{h}=\gamma_{y}=\frac{A(1-\bar{n})-\rho+\beta(1-\sigma)(\phi+\omega) b \bar{n}^{\theta}}{\sigma-\beta \phi(1-\sigma)}>0 \\
\gamma_{E} & =\phi \gamma+(\phi+\omega) b \bar{n}^{\theta}>0
\end{aligned}
$$

Proof. See appendix A.

The first condition in Proposition 1, stating that the productivity of capital needs to be large enough but not too large, is required to ensure that the rate of economic (and environmental) growth is positive and to rule out explosive paths, as standard in the AK literature. The second condition is instead needed to ensure that the child rearing time is a share of available time, which as standard both in the endogenous fertility (Marsiglio, 2011) and in the growth and environment (Mohtadi, 1996) literature requires the inverse of the intertemporal elasticity of substitution to be smaller than one. Provided that these conditions are met the BGP equilibrium is sustainable since associated with increases in output and improvements in the health of the environment, as extensively shown in the growth and environment literature whenever the production function is assumed to be linear (Smulders, 1999). According to Proposition 1 the growth rate of the environment is proportional to the economic growth rate and specifically it is a linear combination of the economic and demographic growth rates. The result that environmental quality increases with both output and population growth is related to the linear specification of the production function, which also implies that the economy does not show any transitional dynamics as in canonical AK-type models. The BGP equilibrium needs thus to be interpreted as a long run representation only of economic, demographic and environmental outcomes.

Our main goal is examining the relationship between demographic changes (measured by $n$ since the birth rate and the time allocated to nurturing are monotonically related) and both economic and environmental performance. Specifically, we focus first on how economic growth and environmental outcomes are related to population change whenever all exogenous factors are controlled for, that is the optimal fertility rate is treated simply as a parameter (see Yip and Zhang, 1996, 1997), and we will see later how the results differ when some exogenous factor is allowed to vary.

\subsection{Constant Exogenous Factors}

Let us now consider a situation in which all exogenous factors are controlled for, and let us analyze the economic growth and fertility nexus. From (7) it is clear that the impact of child rearing time on economic growth is not unambiguously monotonic. Indeed, it crucially depends on the size of the fertility rate since:

$$
\frac{\partial \gamma}{\partial \bar{n}}=\frac{\beta(1-\sigma)(\phi+\omega) b \theta \bar{n}^{\theta-1}-A}{\sigma-\beta \phi(1-\sigma)} .
$$

The previous expression shows that the impact of fertility on economic performance is determined by two factors. The latter term, $\frac{-A}{\sigma-\beta \phi(1-\sigma)}$, represents what we may label as the "output effect" since it is directly related to the use of time for productive purposes; even if slightly different from previous studies which mainly focus on capital dilution (Solow, 1956), its qualitative implications are the same, suggesting that as the population size increases economic performance tends to fall. The former term, $\frac{\beta \theta(1-\sigma)(\phi+\omega) b \bar{n}^{\theta-1}}{\sigma-\beta \phi(1-\sigma)}$, represents what we may refer to as the "environment effect" since it measures how fertility affects economic growth through the environment channel; such a factor has never been analyzed thus far, and it suggests that 
economic performance could even rise in response to an increase in the population size because of households' concern for the environment. The net impact of population on economic growth depends on which of the two effects dominates. Specifically, as long as the environment effect is smaller than the output effect the relationship between economic performance and fertility is decreasing, while whenever the environment effect dominates the relationship becomes increasing. It is thus straightforward to state the following result.

Proposition 2. Along the BGP, economic growth may be non-monotonically related to the population growth rate. Whenever the environment effect is larger (smaller) than the output effect, population growth increases (decreases) economic performance.

The eventual existence of a non-monotonic relationship between growth and demography, as per Proposition 2, is consistent with empirical evidence (Kelley and Schmidt, 1995; Boikos et al., 2013), which shows that population growth enhances economic performance when the fertility rate is small (i.e., $\bar{n}^{1-\theta}<\frac{\beta \theta(1-\sigma)(\phi+\omega) b}{A}$ ) while it becomes a burden for growth when it is large (i.e., $\bar{n}^{1-\theta}>\frac{\beta \theta(1-\sigma)(\phi+\omega) b}{A}$ ). Note that in absence of environmental concern the traditional Malthusian relation between population and economic growth is restored; indeed, whenever $\beta=0$, economic growth monotonically decreases with fertility, suggesting that a minimum degree of care for the environment is essential for reconciling theory with empirics. Other mechanisms allowing to obtain a similar result are related to the eventual existence of multiple indeterminate equilibria (Yip and Zhang, 1997), the presence of a non-monotonic dilution function in capital accumulation (Boucekkine and Fabbri, 2013), and the degree of efficiency of public education (Prettner, 2014). However, to the best of our knowledge, none of the existing explanations argues that environmental quality though agents' concern for the environment might play a role.

Let us now move to the analysis of the relationship between demographic changes and environmental performance. As for the growth and fertility relationship, from (8) it is clear that the impact of the nurturing time on environmental growth is not unambiguously determined since:

$$
\frac{\partial \gamma_{E}}{\partial \bar{n}}=\frac{\beta \phi(1-\sigma)(\phi+\omega) b \theta \bar{n}^{\theta-1}-A \phi}{\sigma-\beta \phi(1-\sigma)}+(\phi+\omega) b \theta \bar{n}^{\theta-1} .
$$

How demographic growth affects environmental performance depends on two different effects. The former term, $\phi \frac{\partial \gamma}{\partial \bar{n}}$, represents what we may label as the "growth effect" suggesting that increases in the fertility rate, through the economic performance channel, tend to positively or negatively affect environmental quality according to whether the environment or the output effect dominates. The latter, $(\phi+\omega) \frac{\partial \gamma_{N}}{\partial \bar{n}}>0$, represents what we may refer to as the "population effect" suggesting that increases in the fertility rate tend to improve environmental performance through the population size channel $9^{9}$ The net effect of a change in the nurturing time on the growth of environmental quality depends on which of the two effects dominates. Specifically, economic and environmental performance will go hand-in-hand in response to variations of the child rearing time in two alternative cases. The first case is represented by a situation in which fertility positively affects both (7) and (8), and this happens whenever the environment effect is larger than the output effect. The second case is represented by a situation in which both the economic and environmental growth rates are negatively affected by fertility, and this requires the output effect to be larger than the environment effect and simultaneously the growth effect to be larger than the population effect. In any other case the impact of changes in the fertility rate will induce variations of different sign on economic growth and environmental quality, thus demographic policies will be unable to achieve win-win outcomes 10 . This allows us to claim the following.

\footnotetext{
${ }^{9}$ This result is consistent with the "cornucopian view", claiming that population pressure since promoting technological progress may lead to improvements in environmental performance. See Panayotou (2000) for a review of different views on the population and environment relation, and in particular of the debate between neo-Malthusians and cornucopians.

${ }^{10}$ Porter and van der Linde's (2002) seminal paper firstly stresses how it might be possible that in certain circumstances policies designed to specifically address environmental problems result in promoting economic performance, leading thus to improvements in environmental quality and economic growth at the same time. Their original argument is related to the fact
} 
Proposition 3. If the output effect is smaller than the environment effect, then along the BGP increases in the child rearing time will be win-win, leading to increases in both economic and environmental performance. If the output effect is large enough (i.e., larger than the environment effect, such that also the growth effect is larger than the population effect), then reductions in the child rearing time will be win-win.

Proposition 3 clearly shows that in some specific circumstances demographic policies might be a very effective tool in order to achieve win-win outcomes. The type of policy needed in order to implement a win-win outcome is strictly related to the non-monotonicity in the economic performance and fertility relationship. Specifically, as long as the fertility rate is small, population growth enhances both economic and environmental performances, thus policies aiming at increasing the time allocated to nurturing might increase both the economic and environmental growth rates. However, whenever the fertility rate is large, population growth is a burden both for economic and environmental performances, thus policies aiming at reducing the time allocated to nurturing activities should be promoted. Note that there exists also situations in which (demographic policy driven) win-win outcomes do not exist since the output effect is not large enough to allow the growth effect to more than compensate the population effect. Proposition 3 suggests thus that in order to achieve win-win outcomes which type of policy should be promoted depends upon the speed of demographic growth experienced in specific economies. Specifically, in industrialized economies where the rate of population growth is low (generally below the replacement rate) policies aiming to raise fertility might need to be supported; in developing countries where the rate of population growth is high, instead, policies reducing fertility might need to be favored. Since demographic trends suggest that in the near future an increasing share of global emissions will be due to developing countries (IPCC, 2015), the promotion of population control policies in these countries seems the priority in order to address the world economy towards a sustainable development path.

\subsection{Varying Exogenous Factors}

Apart from the case in which exogenous factors are all constant, the implementation of win-win policies is not straightforward since fertility is endogenously determined, thus understanding how to eventually affect the population growth rate in order to achieve the desired economic and environmental outcomes is not simple. Indeed, thus far we have focused on a situation in which all exogenous factors are controlled for, while whenever we let them vary, thus we do not consider the optimal fertility rate simply as a parameter, the results may be more sophisticated (Yip and Zhang, 1996, 1997). Demographic policies are mainly effective in modifying the opportunity cost of having children, thus let us consider how a change in the remuneration rate $\left(w_{t}=A\right)$ may impact on population, economic and environmental growth rates ${ }^{11}$. Even if the relation between the remuneration rate and the fertility rate is clearly monotonic $\left(\frac{\partial \bar{n}}{\partial A}=-\frac{\bar{n}}{(1-\theta) A}<0\right)$, how $A$ affects economic and environmental growth rates is not unambiguously determined since the following results hold:

$$
\begin{aligned}
\frac{\partial \gamma}{\partial A} & =\frac{\sigma(1-\theta)+\bar{n}\left[\theta \sigma-\beta \phi(1-\sigma)^{2}(\phi+\omega)\right]}{\sigma(1-\theta)[\sigma-\beta \phi(1-\sigma)]} \\
\frac{\partial \gamma_{E}}{\partial A} & =\frac{\phi(1-\theta)+\bar{n}[\theta \phi-(1-\sigma)(\phi+\omega)]}{(1-\theta)[\sigma-\beta \phi(1-\sigma)]}
\end{aligned}
$$

that environmental policy might result in enhanced competitiveness eventually benefitting also economic growth. Such a notion of win-win opportunity has often been interpreted in a broader sense to refer to anything which might lead to simultaneous improvements in economic and environmental performance. As in Ansuategi and Marsiglio (2016) we use the term "win-win outcome" to refer to any outcome in which some policy tool (and in particular population growth, affected through population policy as we shall discuss more formally later) can be used to promote growth and environmental improvements.

${ }^{11} \mathrm{~A}$ change in $w_{t}$ may be directly implemented through a change in tax rate on (labor). A government by simply taxing income at a rate $\zeta \in(0,1)$ to finance even unproductive public expenditure, can modify the capital accumulation equation as follows: $\dot{H}_{t}=(1-\zeta)\left(1-n_{t}\right) w_{t} H_{t}-N_{t} c_{t}$; thus, any change in $\zeta$ will lead to a result equivalent (even if with opposite sign) to a change in $w_{t}$. 
Differently from what previously discussed, in this framework since $A$ affects $\gamma$ and $\gamma_{E}$ both directly and indirectly (through its impact on $\bar{n}$ ) it is not possible to distinguish between either output and environment effects, or growth and population effects. The overall effect is however ambiguous, and clearly the value of different parameters determine whether the above expressions turn out to be positive or negative. Note that from (11) and (12) we can conclude that results similar to those illustrated in Propositions 2 and 3 hold. Indeed, the relationship between economic and demographic growth (through the effect induced by the change in $A$ ) may be non monotonic; however, in the case of absence of environmental concern, a traditional Malthusian relation is restored (an increase in the remuneration rate, by lowering the fertility rate increases the economic growth rate). Moreover, if certain parametric conditions are met win-win outcomes driven by demographic policies may exist; specifically, whenever $\theta>\frac{(1-\sigma)(\phi+\omega)}{\phi}$ a reduction in the population growth rate (induced by an increase in the remuneration rate) simultaneously increases both economic and environmental growth rates, suggesting that in such a case the implementation of win-win policies may be straightforward.
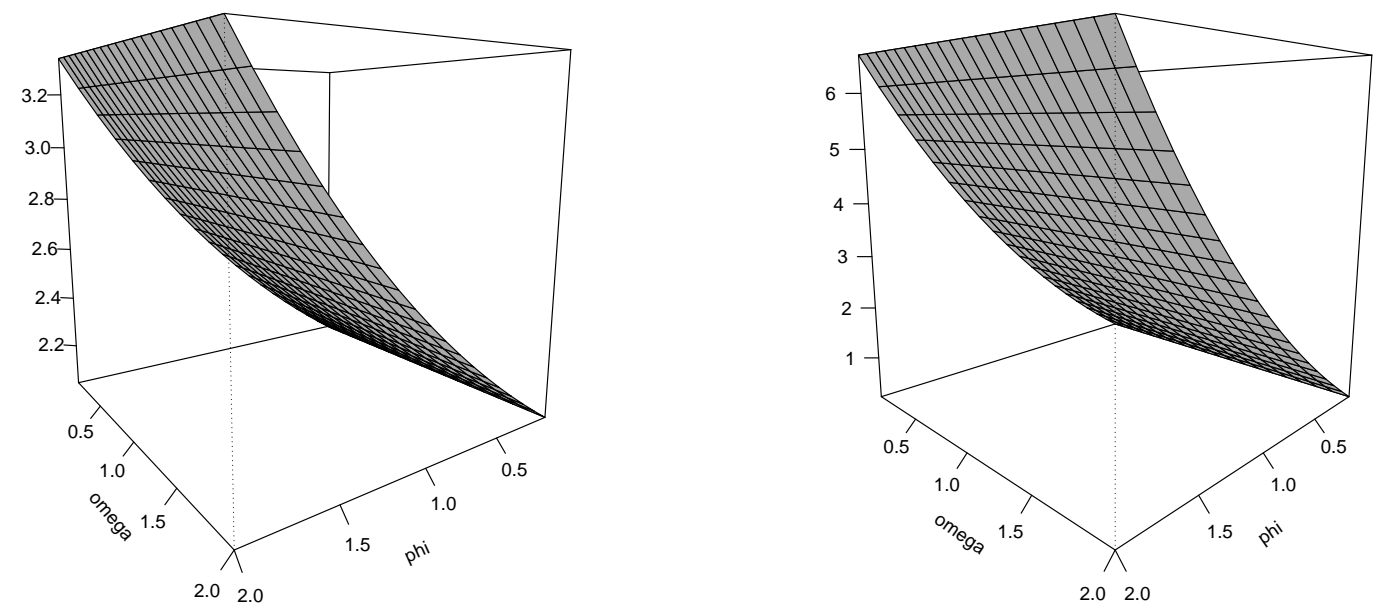

Figure 1: Derivative of economic (left panel) and environmental (right panel) growth rates with respect to $A$ for varying $\phi$ and $\omega$.

In order to test also whether such a (sufficient) condition is likely to be met in real world applications, we consider a realistic model's parametrization. In accordance with the conditions in Proposition 1, we set the parameter values as follows: $\sigma=0.5$ (Marsiglio, 2014), $\rho=0.04$ and $A=1$ (Mullingan and Sala-iMartin, 1993), $\beta=0.2$ (Mohtadi, 1996), $b=0.05$ and $\theta=0.5$ (Tournemaine and Luangaram, 2012), and we let $\phi$ and $\omega$ vary between 0 and 2 in order to see whether and how different degrees of environmental impacts of output and population, respectively, are going to affect our results 12 Indeed, estimates from the STIRPAT equation about the elasticity of population and affluence are very mixed, varying from inelastic to elastic results (Rosa and Dietz, 2012). Even if for the specific range of parameter values the sufficient condition $\theta>\frac{(1-\sigma)(\phi+\omega)}{\phi}$ is never met, it is possible to conclude that both 11 and 12 are positive. Figure 1 illustrates how the above expressions change with $\phi$ and $\omega$, and it is clear that within the considered range of these two parameters they are always positive. Along the BGP, the traditional Malthusian conjecture (Malthus, 1798) seems to hold true and to be further reinforced: indeed, there is not only an inverse relationship between economic growth and population growth, but also between environmental performance

\footnotetext{
${ }^{12}$ Note that for the above set and range of parameters, the technical conditions in Proposition 1 are always met suggesting thus that a non-empty (and not narrow) set of realistic parameter values consistent with such conditions does exist.
} 
and population growth. Thus, demographic change may be detrimental not only for the economy but also for the environment. This suggests that by increasing the (labor) remuneration rate (through for example some subsidy) it is possible to rise both economic and environmental performance, via a reduction in the fertility rate. These results show that despite the little emphasis placed by policymakers on demographic policy, such a kind of policy might be easily implemented and it might also be very effective in order to achieve a more sustainable growth. Thus, further analysis on the eventual impacts of demography on both the economy and environment might be needed.

\section{Demographic Policy}

We now turn to the analysis of optimal policy, and in particular we focus on the potential role of demographic policy in improving both economic and environmental performance. While the potential role of demographic policy in affecting economic growth has been extensively discussed following the quantity-quality children trade-off literature (Becker and Lewis, 1973), the implications of population policy for environmental quality have been only seldom discussed. To the best of our knowledge, Cronshaw and Requate (1997) are the first to analyze the effects of changes in the population size on environmental quality by relying on a simple static approach. Harford (1997, 1998), Jöst and Quaas (2010), and Schou (2002) under different setups discuss the effects of population growth on the environment in a dynamic setting by mainly focusing on the role of economic policy to restore the social optimum in the decentralized outcome. Differently from these works, we stress how population policy can be used to eventually achieve win-win outcomes and to maximize economic (or environmental) performance, stabilizing thus the otherwise non-monotonic relation between population and economic growth.

Since from our previous analysis the results are not qualitatively different by keeping constant or allowing exogenous factors to change, for the sake of simplicity we consider a framework with constant exogenous factors. In order to understand to what extent demographic policy might affect economic and environmental outcomes, it is enough to notice that both the economic and environemtnal growth rates are concave functions of fertility, and thus there exist both an economic growth maximizing, $\bar{n}_{\gamma}$, and an environmental growth maximizing, $\bar{n}_{\gamma_{E}}$, fertility rate. From $(9)$ and $(10)$ it is straightforward to determine these rates as follows:

$$
\begin{aligned}
\bar{n}_{\gamma} & =\left[\frac{\beta(1-\sigma)(\phi+\omega) b \theta}{A}\right]^{\frac{1}{1-\theta}} \\
\bar{n}_{\gamma_{E}} & =\left[\frac{\sigma(\phi+\omega) b \theta}{\phi A}\right]^{\frac{1}{1-\theta}}
\end{aligned}
$$

where $\bar{n}_{\gamma_{E}}>\bar{n}_{\gamma}$ follows from the parameter restrictions in Proposition 1 . Note that the equilibrium fertility rate in (6) is generally different from both (13) and (14), suggesting thus that population policies can be used to effectively maximize either economic growth or environmental performance. Indeed, whenever $\phi \geq \frac{(1-\sigma) \omega}{\sigma}$ the fertility rate $\bar{n}$ is greater than both $\bar{n}_{\gamma_{E}}$ and $\bar{n}_{\gamma}$ (i.e., $\bar{n}>\bar{n}_{\gamma_{E}}>\bar{n}_{\gamma}$ ), while whenever $\phi<\frac{(1-\sigma) \omega}{\sigma}$ the population growth rate $\bar{n}$ is lower than both $\bar{n}_{\gamma_{E}}$ and $\bar{n}_{\gamma}$ (i.e., $\bar{n}_{\gamma_{E}}>\bar{n}_{\gamma}>\bar{n}$ ). This means that specifically designed demographic policies aiming at affecting $\bar{n}$ might allow to achieve either the maximal economic performance or the maximal environmental performance, but maximizing both economic and environmental performance simultaneously is not possible. Understanding whether the fertility rate should be increased or decreased in order to improve either economic growth or environmental performance is however not straightforward since this crucially depends on the relative size of $\phi$ and $\omega$, measuring the pollution elasticities of affluence and population, respectively. Since empirical evidence on these parameters is mixed (Rosa and, Dietz, 2012), which of the two outcomes is most likely to occur cannot be said a priori. Despite the lack of clear empirical evidence, the existence of economic and environmental growth maximizing fertility rates suggests that policymakers can effectively intervene in order to stabilize the nonmonotonic relations between economic and environmental performance and population growth. Indeed, by 
implementing either (13) or (14), either economic performance or environmental performance will turn out to be completely independent from population change, and thus demographic policy might be used in an effective way to get rid of the uncertainty that the existence of a non-monotonic relation might imply.

In order to look at how such a result may be achieved, let us consider an explicit population policy, and let us consider the implementation of the economic growth maximizing fertility rate, $\bar{n}_{\gamma}$. Let us focus on child-support or child-control policy financed via lump-sum, and we denote with $\tau \in(-1,1)$ the policy rate which can be positive or negative in the case of a subsidy or a tax, respectively. Such a type of policy affects the fertility rate which along the BGP turns out to be equal to $\bar{n}^{*}=\left[\frac{\sigma \theta(1+\tau) b}{(1-\sigma) A}\right]^{\frac{1}{1-\theta}}$, suggesting thus that positive (negative) values of $\tau$ tend to increase (decrease) the fertility rate. It is straightforward to verify that the optimal policy instruments in order to implement the growth maximizing fertility rate $\bar{n}_{\gamma}$ is equal to $\tau_{\gamma}^{*}=\frac{\beta(1-\sigma)^{2}(\phi+\omega)-\sigma}{\sigma}$, which intuitively turns out to be positive if $\phi<\frac{(1-\sigma) \omega}{\sigma}$ (that is whenever $\bar{n}<\bar{n}_{\gamma}$, such that the fertility rate needs to be increased) or negative if $\phi \geq \frac{(1-\sigma) \omega}{\sigma}$ (that is whenever $\bar{n}>\bar{n}_{\gamma}$, such that the fertility rate needs to be decreased) 13 The sign of the policy instrument is crucially related to the relative size of the output and the environment effect which determines whether the fertility rate in the unregulated economy is lower or higher than the optimal growth maximizing rate. This result is summarized in the following proposition.

Proposition 4. The economic performance maximizing fertility rate can be achieved with an appropriate population policy. Such a policy needs to take the form of child-support (child-control) whenever the environment (output) effect dominates.

Proposition 4 suggests that population policy can be an effective tool to achieve the maximal economic performance. Similarly, the maximal environmental performance may be achieved with an appropriate tax or subsidy, suggesting that even without relying on specific environmental policy policymakers may be able to affect (and improve) environmental outcomes through population policy. Therefore, demographic policy does represent an alternative tool to carbon taxes and other traditional environmental policy tools to achieve specific environmental goals. Moreover, since fertility does not affect the instantaneous utility while environmental quality does, it might even be possible that demographic policy allows to achieve the same long run environmental goal with lower welfare costs than other direct environmental policies. This allows us to stress once again how, despite the little emphasis placed by policymakers on demographic policy, population policy should be fully taken into consideration as a potential tool to achieve not only economic but also environmental targets. This calls for the need of additional efforts both from a theoretical and empirical point of view to assess the effective desirability and validity of population policy.

\section{Conclusion}

This paper represents a first attempt to analyze the mutual relationships among endogenous population change, economic growth and environmental quality. We extend a traditional model of endogenous growth with endogenous fertility to account for the environmental interactions induced by pollution. As stated by the IPAT equation, we assume that both the population size and production activities impact (with different intensities) on the environment. In its simplicity our model is striking and allows to stress two different kind of results. First, environmental quality, through its impact on utility, represents a potential source of non-monotonicity in the population and economic growth nexus often found in empirical studies. Second, demographic policy, by simultaneously affecting both economic and environmental performance (through the capital accumulation and pollution channel, respectively), might allow to achieve win-win

\footnotetext{
${ }^{13}$ Similar results apply for what concerns the implementation of the environmental performance fertility rate. In this case, the optimal policy instrument to implement $\bar{n}_{\gamma_{E}}$ is equal to $\tau_{\gamma_{E}}^{*}=\frac{\omega(1-\sigma)-\phi \sigma}{\phi}$, which again turns out to be positive if $\phi<\frac{(1-\sigma) \omega}{\sigma}$ (since $\bar{n}<\bar{n}_{\gamma_{E}}$ ) or negative if $\phi \geq \frac{(1-\sigma) \omega}{\sigma}\left(\right.$ since $\left.\bar{n}>\bar{n}_{\gamma_{E}}\right)$.
} 
outcomes, meaning that even in absence of specific environmental policy demographic policy can be used to improve environmental outcomes. Even if these results are straightforward whenever all exogenous factors are controlled for, when we allow them to vary the picture becomes a bit more complicated. However, also in such a framework we can conclude, supported also by a numerical example, that demographic policies may be very important in order to achieve a more sustainable development process. We also show that specifically designed population policies can be effectively used in order to stabilize the otherwise nonmonotonic relation between economic (or environmental) performance and population growth. Whether this requires to incentivize or disincentize demographic growth strictly depends on whether the output or the environment effect dominates.

Our model thus represents a simple but interesting benchmark in order to understand the mutual implications among demography, economy and environment. However, note that in order to maintain the model tractable we do not consider abatement activities or other channels enriching the economic and environmental linkages. Specifically, the evolution of demography considered is extremely simplistic since abstracting completely from mortality and its eventual dependency upon environmental quality (Varvarigos, 2011); also the impact of environmental quality on capital accumulation via production externalities is not analyzed (Bosi and Desmarchelier, 2013). Moreover, other popular issues on the growth and demography relationship are not considered, while the analysis could be related to technological progress (Strulik et al., 2013) and the optimal population size problem (Marsiglio, 2014). Extending the analysis along these directions is a challenging task for future research.

\section{A Steady State and Transitional Dynamics}

From the maximization problem in (1), (2) and (3), it is straightforward to derive the Euler equations for consumption and fertility, which at general equilibrium read as:

$$
\begin{aligned}
\frac{\dot{c}_{t}}{c_{t}} & =\frac{1}{\sigma}\left[A\left(1-n_{t}\right)-\rho+\beta(1-\sigma) \xi-\beta(1-\sigma) \nu \frac{H_{t}^{\phi} N_{t}^{\omega}}{E_{t}}\right] \\
\frac{\dot{n}_{t}}{n_{t}} & =\frac{1}{1-\theta}\left[1-\frac{\sigma \theta b}{(1-\sigma) A} n_{t}^{\theta-1}\right] \frac{c_{t} N_{t}}{H_{t}} .
\end{aligned}
$$

Since the economy shows perpetual growth, it is convenient to analyze the dynamics of a stationary system, by introducing the intensive variables $\chi_{t}=\frac{c_{t} N_{t}}{H_{t}}$ and $\varphi_{t}=\frac{H_{t}^{\phi} N_{t}^{\omega}}{E_{t}}$, representing the (aggregate) consumption to capital and pollution to environment ratio, respectively. This allows us to recast the dynamical system (2), (3), (5), 15), (16) as follows:

$$
\begin{aligned}
\frac{\dot{\chi}_{t}}{\chi_{t}} & =\frac{1-\sigma}{\sigma} A\left(1-n_{t}\right)-\frac{\rho}{\sigma}+\frac{\beta(1-\sigma)}{\sigma} \xi-\frac{\beta(1-\sigma)}{\sigma} \nu \varphi_{t}+b n_{t}^{\theta}+\chi_{t} \\
\frac{\dot{\varphi}_{t}}{\varphi_{t}} & =\phi\left(1-n_{t}\right) A-\phi \chi_{t}+\omega b n_{t}^{\theta}-\xi+\nu \varphi_{t} \\
\frac{\dot{n}_{t}}{n_{t}} & =\frac{1}{1-\theta}\left[1-\frac{\sigma \theta b}{(1-\sigma) A} n_{t}^{\theta-1}\right] \chi_{t} .
\end{aligned}
$$

The equilibrium of the previous system is given by $(\bar{\chi}, \bar{\varphi}, \bar{n})$, where:

$$
\begin{aligned}
\bar{\chi} & =\frac{\rho-(1+\beta \phi)(1-\sigma)(1-\bar{n}) A-[\sigma+\beta \omega(1-\sigma)] b \bar{n}^{\theta}}{\sigma-\beta \phi(1-\sigma)} \\
\bar{\varphi} & =\frac{\phi \rho-\phi(1-\bar{n}) A+[\sigma-\beta \phi(1-\sigma)] \xi-\sigma(\phi+\omega) b \bar{n}^{\theta}}{\nu[\sigma-\beta \phi(1-\sigma)]} \\
\bar{n} & =\left[\frac{\sigma \theta b}{(1-\sigma) A}\right]^{\frac{1}{1-\theta}}
\end{aligned}
$$


Note that for $\bar{n}$ to be positive we need that $\sigma<1$; in order for being also smaller than unity the condition $\sigma<\frac{A}{A+\theta b}<1$ needs to be met. From the concavity of the utility function with respect to environmental quality, it follows that the denominator in 20) and (21) is positive provided that $\sigma>\phi$. For the numerator in 20 to be positive we need $\rho>(1+\beta \phi)(1-\sigma)(1-\bar{n}) A+[\sigma+\beta \omega(1-\sigma)] b \bar{n}^{\theta}$. 21 turns out to be positive provided that $\xi$ is large enough. By plugging (21) in (15) and (5), we obtain the growth rate of consumption and environmental quality, respectively, along the BGP equilibrium as in (7) and (8). Note that for $\gamma$ to be positive we also need that $\rho<(1-\bar{n}) A+\beta(\phi+\omega)(1-\sigma)] b \bar{n}^{\theta}$. These conditions jointly require that $\left.(1+\beta \phi)(1-\sigma)(1-\bar{n}) A+[\sigma+\beta \omega(1-\sigma)] b \bar{n}^{\theta}<\rho<(1-\bar{n}) A+\beta(\phi+\omega)(1-\sigma)\right] b \bar{n}^{\theta}$, which makes full sense provided that $A$ is large enough. Note that such parametric restrictions make sure the maximized Hamiltonian is jointly concave in the state variables suggesting that first order necessary conditions are also sufficient for a maximum, and thus the BGP equilibrium represents the optimal solution of our optimization problem.

By linearization, we can assess the stability of the equilibrium $(\bar{\chi}, \bar{\varphi}, \bar{n})$. The Jacobian matrix, $J\left(\chi_{t}, \varphi_{t}, n_{t}\right)$, evaluated at steady state is:

$$
J(\bar{\chi}, \bar{\varphi}, \bar{n})=\left[\begin{array}{ccc}
\bar{\chi} & -\frac{\beta(1-\sigma)}{\sigma} \nu \bar{\chi} & 0 \\
-\phi \bar{\varphi} & \nu \bar{\varphi} & \frac{\omega(1-\sigma)-\phi \sigma}{\sigma} A \bar{\varphi} \\
0 & 0 & \bar{\chi}
\end{array}\right] .
$$

It is straightforward to compute the eigenvalues of the Jacobian, $\vartheta$, which read as, $\vartheta_{1}=\bar{\chi}$ and $\vartheta_{2,3}=$ $\frac{1}{2}\left[\nu \bar{\varphi}+\bar{\chi} \pm \sqrt{(\nu \bar{\varphi}+\bar{\chi})^{2}-\frac{4[\sigma-\beta \phi(1-\sigma)]}{\sigma} \nu \overline{\varphi \chi}}\right]$. It is clear that $\vartheta_{1}$ is positive while $\vartheta_{2}$ and $\vartheta_{3}$ have both positive real parts, independently on whether the term inside the square root is positive or negative. Since all the eigenvalues are positive, the system (17), (18), (19) is unstable. This implies that, as we expected being the model an AK-type model, the economy does not show any transitional dynamics and lies on its long run BGP equilibrium from time 0 onward.

\section{References}

1. Ansuategi, A., Marsiglio, S. (2016). Is environmental protection expenditure beneficial for the environment?, Review of Development Economics, DOI: 10.1111/rode.12267

2. Azomahou, T.T., Mishra, T., Parhi, M. (2015). Economic growth under stochastic population and pollution shocks, Manchester School 83, 314-345

3. Barro, R.J., Becker, G.S. (1989). Fertility choice in a model of economic growth, Econometrica 57, 481-501

4. Barro, R.J., Sala-i-Martin, X. (2004). Economic growth (Cambridge, Massachusetts: MIT Press)

5. Becker, G.S., Lewis, H.G. (1973). On the interaction between the quantity and quality of children, Journal of Political Economy 81, S279-S288

6. Bloom, D.E., Canning, D., Sevilla, J. (2003). The demographic dividend: a new perspective on the economic consequences of population change (Santa Monica, CA: Rand, MR-1274)

7. Boikos, S., Bucci, A., Stengos, T. (2013). Non-monotonicity of fertility in human capital accumulation and economic growth, Journal of Macroeconomics 38, 44-59

8. Boserup, E. (1989). Population and technical change: a study of long-term trends (University of Chicago Press: Chicago)

9. Bosi, S., Desmarchelier, D. (2013). Demography and pollution, Research in Economics 67, 316-323

10. Boucekkine, R., Fabbri, G. (2013). Assessing Parfit's repugnant conclusion within a canonical endogenous growth set-up, Journal of Population Economics 26, 751-767 
11. Boucekkine, R., Martinez, B., Ruiz-Tamarit, R. (2014). Optimal sustainable policies under pollution ceiling: the demographic side, Mathematical Modelling of Natural Phenomena 9, 38-64

12. Cigno, A. (1981). Growth with exhaustible resources and endogenous population, Review of Economic Studies 48, 281-287

13. Cole, M.A., Neumayer, E. (2004). Examining the impact of demographic factors on air pollution, Population and Environment 26, 5-21

14. Constant, K., Nourryb, C., Seegmuller, T. (2014). Population growth in polluting industrialization, Resource and Energy Economics 36, 229-247

15. Cronshaw, M.B., Requate, T. (1997). Population size and environmental quality, Journal of Population Economics 10, 229-316

16. Dasgupta, P. (1995). The population problem: theory and evidence, Journal of Economic Literature 33, 1879-1902

17. Ebert, U., Welsch, H. (2007). Environmental emissions and production economics: implications of the materials balance, American Journal of Agricultural Economics 89, 287-293

18. Ehrlich, P., Holdren, J. (1971). The impact of population growth, Science 171, 1212-1217

19. Galeotti, M., Lanza, A., Piccoli, M.G.L. (2011). The demographic transition and the ecological transition: enriching the environmental Kuznets curve hypothesis, IEFE - Center for Research on Energy and Environmental Economics and Policy, Working Paper 44

20. Galindev, R. (2011). Leisure goods, education attainment and fertility choice, Journal of Economic Growth 16, 157-181

21. Harford, J.D. (1997). Stock pollution, child-bearing externalities, and the social discount rate, Journal of Environmental Economics and Management 33, 94-105

22. Harford, J.D. (1998). The ultimate externality, American Economic Review 88, 260-265

23. Jöst, F., Quaas, M.F. (2010). Environmental and population externalities, Environment and Development Economics 15, 1-19

24. Harisson, P. (1994). The third revolution: population, environment and a sustainable world (London: Penguin)

25. Intergovernmental Panel on Climate Change (2015). Climate change 2014: synthesis report (Geneva, Switzerland: IPCC)

26. Kaya, Y. (1990). Impact of carbon dioxide emission control on GNP growth: interpretation of proposed scenarios (IPCC Energy and Industry Subgroup, Response Strategies Working Group)

27. Kelley, A.C. (1988). Economic consequences of population change in the third world, Journal of Economic Literature 26, 1685-1728

28. Kelley, A.C., Schmidt, R.M. (1995). Population and economic growth correlations: the role of the components of demographic change, Demography 32, 543-555

29. Lutz, W., Prskawetz, A., Sanderson, W.C. (2002). Introduction, in (Lutz, W., Prskawetz, A., Sanderson, W.C. Eds.) "Population and environment: methods of analysis", 1-21 (New York: The Population Council)

30. Malthus, T.R. (1798). An essay on the principle of population (London: J. Johnson), in Library of Economics and Liberty

31. Marsiglio, S. (2011). On the relationship between population change and sustainable development, Research in Economics 65, 353-364

32. Marsiglio, S. (2014). Reassessing Edgeworth's conjecture when population dynamics is stochastic, Journal of Macroeconomics 42, 130-140

33. Mohtadi, H. (1996). Environment, growth, and optimal policy design, Journal of Public Economics $63,119-140$ 
34. Mullingan, C.B., Sala-i-Martin, X. (1993). Transitional dynamics in two-sector models of endogenous growth, Quarterly Journal of Economics 108, 739-773

35. National Academy of Sciences (1992). Policy implications of greenhouse warming: mitigation, adaptation, and the science base, Panel on Policy Implications of Greenhouse Warming (Washington, DC: National Academy Press)

36. Nerlove, M. (1991). Population and the environment: a parable of firewood and other tales, American Journal of Agricultural Economics 73, 1334-1347

37. Panayotou, T. (2000). Population and environment, Center for International Development at Harvard University, Working Paper 54

38. Peretto, P., Valente, S. (2015). Growth on a finite planet: resources, technology and population in the long run, Journal of Economic Growth, forthcoming

39. Porter, M.E., van der Linde, C. (1995). Toward a new conception of the environment-competitiveness relationship, Journal of Economic Perspectives 9, 97-118

40. Prettner, K. (2014). The non-monotonous impact of population growth on economic prosperity, Economics Letters 124, 93-95

41. Ramsey, F. (1928). A mathematical theory of saving, Economic Journal 38, 543-559

42. Razin, A., Yuen, C.W. (1995). Utilitarian tradeoff between population growth and income growth, Journal of Population Economics 8, 81-87

43. Rosa, E.A., Dietz, T. (1998). Climate change and society: speculation, construction and scientific investigation, International Sociology 13, 421-455

44. Rosa, E.A., Dietz, T. (2012). Human drivers of national greenhouse-gas emissions, Nature Climate Change 2, 581-586

45. Schou, P. (2002). Pollution externalities in a model of endogenous fertility and growth, International Tax and Public Finance 9, 709-725

46. Simon, J.L. (1981). The ultimate resource (Princeton University Press: Princeton)

47. Smulders, S. (1999). Endogenous growth theory and the environment, in: van den Bergh, J. (Ed.), "The Handbook of Environmental and Resource Economics" (Edward Elgar: Cheltenham)

48. Solow, R. (1974). Intergenerational equity and exhaustible resources, Review of Economic Studies 41, $29-45$

49. Smulders, S. (1999). Endogenous growth theory and the environment, in (van den Bergh, J., Ed.), "The Handbook of Environmental and Resource Economics" (Edward Elgar: Cheltenham)

50. Smulders, S., Gradus, R. (1996). Pollution abatement and long-term growth, European Journal of Political Economy 12, 505-532

51. Strulik, H., Prettner, K., Prskawetz, A. (2013). The past and future of knowledge-based growth, Journal of Economic Growth 18, 411-437

52. Tournemaine, F., Luangaram, P. (2012). R\&D, human capital, fertility, and growth, Journal of Population Economics 25, 923-953

53. United Nations Environment Programme (2012). The future we want - Rio +20 outcome document, available on-line at: http://www.uncsd2012.org/thefuturewewant.html

54. Varvarigos, D. (2011). Environmental dynamics and the links between growth, volatility and mortality, Bulletin of Economic Research 65, 314-331

55. Yip, C.K., Zhang, J. (1996). Population growth and economic growth: a reconsideration, Economics Letters 52, 319-324

56. Yip, C.K., Zhang, J. (1997). A simple endogenous growth model with endogenous fertility: indeterminacy and uniqueness, Journal of Population Economics 10, 97-110 
57. Xepapadeas, A. (2005). Economic growth and the environment, in (Mler, K.G., Vincent, J., Eds.), "Handbook of Environmental Economics", vol. 3. (Elsevier: Amsterdam, Netherlands) 